\title{
O PRINCÍPIO DA DESMERCANTILIZAÇÃO NAS POLÍTICAS SOCIAIS
}

\author{
Clóvis Roberto Zimmermann ${ }^{*}$ \\ Marina da Cruz Silva*
}

\begin{abstract}
O presente artigo objetiva tecer discussões sobre um princípio inovador, denominado de desmercantilização, formulado recentemente por Esping-Andersen $(1990,1999,2002)$ e incorporado ao estudo das políticas sociais. A principal proposição do autor, através deste termo desmercantilização, consiste em avaliar o grau de autonomia e independência dos indivíduos em relação ao mercado. As conclusões essenciais advindas da análise em tela evidenciam uma contribuição singular e inovadora, ao enfatizar a importância dos arranjos institucionais das políticas sociais, considerando não somente os direitos e garantias, mas, sobretudo, o entrelaçamento do Estado com o mercado e a família na provisão de políticas sociais.

PALAVRAS-CHAVE: desmercantilização, políticas sociais, proteção social, Estados de Bem-Estar Social.
\end{abstract}

\section{INTRODUÇÃO}

Estudos metanalíticos, no âmbito da literatura contemporânea, revelam que um número significativo de pesquisadores das políticas sociais comunga um pressuposto básico e fundamental: nas sociedades modernas, não há motivos contundentes para questionar a existência e a necessidade das políticas sociais públicas. Isso se deve ao fato de o provimento de serviços sociais como um direito de cidadania ter se tornado um dos maiores fenômenos do século XX. Karl Polanyi chamou esse processo de "a grande transformação". Na análise do sociólogo Ferndinad Tönnies, esse desenvolvimento acarretou a passagem da "comunidade" (Gemeinschaft) à "sociedade" (Gesellschaft). As mudanças ocasionadas nesse processo estão dire-

* Doutor em sociologia pela Universidade de Heidelberg, Alemanha. Professor adjunto de Ciências Políticas da Universidade Federal do Recôncavo da Bahia (UFRB). Centro de Artes, Humanidades e Letras. Centro. Cep: 44300000 - Cachoeira, BA - Brasil. clovis.zimmermann@gmail.com

* * Doutoranda em Psicogerontologia pela Universidade de Erlangen-Nürnberg na Alemanha. Professora assistente do Curso de Serviço Social da Universidade Federal do Recôncavo da Bahia (UFRB). marinacruz@hotmail.com tamente relacionadas à semântica do termo políticas sociais, as quais compreendem a ação do Estado na cobertura de riscos da vida individual e coletiva (Arretche, 1995), ou políticas que dizem respeito à ação do Estado na promoção do bem-estar dos cidadãos (Marshall, 1976).

Várias pesquisas empíricas confirmam, apesar da proliferação da ideologia do fim do Estado de Bem-Estar ${ }^{1}$ em esfera nacional e internacional, que quanto mais desenvolvido, industrializado e com maior renda é um país, maiores são os investimentos em políticas sociais. Estudos de Opielka (2004), Ullrich (2005) Schmidt; Ostheim; Siegel; Zohlnhöfer (2007) e Bangura (2007) demonstram que os países desenvolvidos investem mais de $20 \%$ do Produto Interno Bruto em políticas de proteção social. Por conseguinte, esses países possuem os maiores índices de proteção econômica (segurodesemprego), amplos programas de transferência de renda, bem como os menores índices de pobreza. Vale ressaltar que, na maioria dos países europeus, os programas de transferência de renda não ${ }^{1}$ Demo (2002) e Giddens (1996). 
exigem dos indivíduos o cumprimento de contrapartidas ou condicionalidades ${ }^{2}$ para que possam permanecer nos programas, como é o caso da América Latina. Ao contrário, esses países adotam um único critério de permanência: a disponibilidade em aceitar um emprego mediado pelo Estado (Fonseca, 2001, p.145).

A questão central que perpassa a maioria dos estudos sobre políticas sociais atuais consiste em analisar os efeitos positivos das políticas sociais no que tange à melhoria das condições materiais, cobertura de riscos, qualidade de vida e bemestar da população. ${ }^{3}$ Em virtude disso, não tem se constituído objeto central do debate teórico contemporâneo o questionamento em torno da necessidade de existência ou não das políticas sociais, mas "como" elas devem ser formuladas e quais devem ser seus objetivos primordiais. Atentos a esse aspecto, Gero Lenhartd e Claus Offe (2006) criticam os estudos que se debruçam apenas em medir a eficácia das políticas sociais. Para esses estudiosos, tal mecanismo de análise representa um equívoco tecnocrático, haja vista que restringe a análise das políticas sociais exclusivamente aos métodos considerados mais adequados, mais corretos e mais "eficientes", deixando de lado a dimensão política e de conflitos, inerentes às políticas sociais. Portanto, segundo esses autores, não são os resultados numéricos das políticas, os "policy outputs", que produzem impactos, mas as mudanças nas relações sociais, especialmente no que tange ao poder de coerção, ameaças legais e politicamente sancionadas, bem como as oportunidades de realização de interesses. Esses aspectos, sim, determinariam o grau de justiça social das políticas sociais. Destarte, uma pesquisa sociológica na área da política social teria de adotar como objetivo central o de desvendar os mecanismos e condições concretas de geração de novas

2 O Programa Bolsa Família exige contrapartidas e condicionalidades das famílias beneficiárias, tais como a frequência escolar e à saúde.

${ }^{3}$ Vide recente estudo de Weissheimer (2006) sobre o Programa Bolsa Família.

${ }^{4}$ Não se trata de estudar a funcionalidade das políticas sociais, mas, sobretudo, os arranjos institucionais estabelecidos na relação entre Estado e sociedade. oportunidades, ocasionadas a partir e após a introdução das políticas sociais.

Seguindo a linha de Marx e Polany, EspingAndersen (1990) inovou ao formular uma concepção mais ampla e "generosa" de se analisar as políticas sociais, isto é, concebê-las e estudá-las à luz das possibilidades de desmercantilização (decommodification) ${ }^{5}$ das relações sociais. Em outros termos, isso implica analisar as políticas sociais tendo como referência o grau de autonomia e independência que essas políticas conseguem garantir aos indivíduos e (ou) famílias de sobreviverem para além das relações do mercado. Conforme esse autor, uma definição mínima da concepção de desmercantilização deve incorporar a possibilidade de cada cidadão em decidir e (ou) optar livremente por não trabalhar quando assim considerar ou julgar necessário, ${ }^{6}$ podendo e tendo como sobreviver dignamente para além da participação no mercado (Esping-Andersen, 1990, p.23). Outrossim, desmercantilização refere-se ao grau em que indivíduos podem manter um nível de vida tolerável, independentemente da obrigação de participarem no mercado de trabalho. As políticas sociais devem, portanto, ser concebidas pelos Estados de Bem-Estar, que regulam a oferta e a demanda de trabalho. Para Merrien (2002), esses Estados podem ser classificados em fortes, médios ou fracos quanto à possibilidade de oferecerem legalmente aos indivíduos oportunidade de saírem mais ou menos fortes em relação ao mercado. ${ }^{7}$ Em virtude disso, Draibe e Riesco (2006) qualificam a concepção de desmercantilização como uma característica inovadora do direito social de cidadania.

Esping-Andersen (1990) salienta que a luta pela desmercantilização sempre foi a principal prio-

\footnotetext{
${ }^{5}$ Alguns autores e traduções de Esping-Andersen utilizam o termo desmercadorização. Contudo, como o termo "Dekommodifizierung" vem diretamente de Karl Marx, optamos por utilizar o termo desmercantilização, por ser o que mais se aproxima do sentido da tradução de Marx no Brasil.

${ }^{6}$ Ao ter condições de recusar trabalhos degradantes (trabalho escravo, trabalhos mal pagos), o indivíduo não seria punido por isso, uma vez que tem assegurado um padrão de sobrevivência, que compreende: estar livre da fome e possuir uma moradia adequada etc.

7 Esping-Andersen (1990) classifica os Estados de BemEstar em três regimes: liberal, conservador e social-democrata. Para maiores informações sobre modelos de
} Estados de Bem-Estar, vide Faria (1998) 
ridade do movimento dos trabalhadores em nível mundial. Quanto mais mercantilizadas as relações, maior seria a dependência de sobrevivência dos trabalhadores em relação ao mercado. Isso dificultaria enormemente o processo de mobilização dos trabalhadores com vistas a ações solidárias. ${ }^{8}$ Ademais, a desmercantilização fortaleceria a organização e a luta dos trabalhadores e enfraqueceria o poder e a autoridade dos patrões, sobretudo daqueles mais autoritários. Isso explica, em parte, a oposição de muitos empresários em relação à introdução, concepção e implementação de políticas sociais com um viés desmercantilizador.

Portanto, a desmercantilização pode ser compreendida como uma pré-condição para que os trabalhadores tenham um nível tolerável de bem-estar e segurança social. Sem desmercantilização, os trabalhadores teriam maiores dificuldades em agir coletivamente. No quadro atual das políticas sociais brasileiras, a discussão sobre a desmercantilização é relativamente nova, sendo necessário um maior aprofundamento acerca dessa forma singular de conceber e analisar as políticas sociais. Constitui, pois, um dos objetivos deste artigo realizar breves apontamentos sobre a concepção de desmercantilização nas políticas sociais, tendo como referência os estudos de Esping-Andersen ${ }^{9}$ (1990, 1999, 2002).

${ }^{8}$ A abordagem de Esping-Andersen difere completamente de muitos paradigmas das políticas sociais em voga no Brasil, que defendem a tese de que as políticas sociais servem quase que exclusivante aos interesses de acumulação e legitimação dos capitalistas. Pedro Demo (2002) é um dos defensores da tese de que as políticas sociais figurariam como defensoras dos interesses dos capitalistas e causariam apatia política aos pobres. Para esse autor, as políticas sociais teriam como consequência a diminuição dos protestos por parte dos pobres, pois eles se acomodariam às suas péssimas condições de vida, capitulariam, deixando de lutar por uma transformação no sistema. A consequência disso seria o reforço e uma maior legitimação do próprio sistema capitalista, uma forma de melhor dominar e explorar os trabalhadores. Ao invés de causar conflitos, as políticas sociais vinculadas a Programas de Transferência de Renda causariam a pacificação dos conflitos e a harmonia entre as classes sociais, mantendo-se, com isso, a ordem social vigente. Além disso, não nasceria uma cidadania ativa, protagonista, mas cidadãos passivos, subalternos, apolíticos, mergulhados na pobreza política (Demo, 2002). Diferentemente dessa análise, Esping-Andersen, concebe as políticas sociais como uma pré-condição para a emancipação de trabalhadores, desempregados e outras categorias exploradas pelo capital.

${ }^{9}$ Gosta Esping-Andersen é sociólogo dinamarquês e professor da Universidade Pompeu Fabra (Barcelona). O livro de maior importância de Esping-Andersen chamase "The three worlds of welfare capitalism" ("Os três mundos do capitalismo de bem-estar") 1990.

\section{O PROCESSO DE MERCANTILIZAÇÃO NO CAPITALISMO}

Esping-Andersen (1990) afirma que a mercantilização é um fenômeno típico da sociedade capitalista. Na Idade Média, a sociedade era pouco mercantilizada, e a capacidade de sobrevivência de um indivíduo não era decidida através do contrato de trabalho, mas através do apoio da família, igreja ou senhor feudal. Isso não significa dizer que não havia qualquer forma de mercantilização naquela época. Contudo a grande maioria das pessoas não era dependente única e exclusivamente dos salários, mas possuía diversas formas de subsistência. Com o advento do capitalismo, as formas prémercantilizadas de proteção social foram destruídas, e as possibilidades de os trabalhadores sobreviverem fora das relações de mercado foram colocadas em xeque. Essas relações tornaram-se o centro das atenções dos estudos de Karl Marx, sobretudo a transformação de produtores independentes em assalariados sem propriedades. Para Marx, a mercantilização da força de trabalho implica a obrigatoriedade da venda da força de trabalho (mercantilização), causando a alienação (Entfremdung) e a consequente liberdade atrás dos muros da prisão.

Vale ressaltar que, na concepção de EspingAndersen (1990), os trabalhadores não deveriam ser tratados como simples mercadorias, uma vez que não têm como ser "retirados do mercado", com o intuito de aumentar os preços da sua força de trabalho, haja vista que não conseguem simplesmente se ausentar por muito tempo do mercado, sobretudo quando não possuem outras formas de sobrevivência. Tratados como mercadorias, os trabalhadores estão expostos a poderes que vão além de suas próprias forças, como ocorre em caso de doenças, eventos macroeconômicos ${ }^{10}$ e ciclos econômicos.

Na opinião de Esping-Andersen (1990), a mercantilização tornou-se uma questão central nas discussões da moderna filosofia e teoria social, de tal modo que os liberais clássicos do laissez-faire se opuseram a qualquer alternativa para além do

${ }^{10}$ Crises econômicas, desemprego etc. 
mercado, uma vez que qualquer intervenção estatal implicaria sacrificar o equilíbrio entre oferta e demanda. Nesse sentido, tanto os liberais clássicos como muitos neoliberais contemporâneos defendem a hipótese de que um mínimo de proteção social não erradicaria a pobreza. Ao contrário, contribuiria para sua perpetuação e institucionalização.

Isso posto, é notório que as correntes teóricas de cunho liberal e socialista divergem quanto à categoria de análise desmercantilização das políticas sociais. Nesse contexto, é mister lembrar que, na história das políticas sociais, os principais conflitos ocorreram entre o grau de imunidade do mercado, sobretudo na força, nos limites e na qualidade dos direitos sociais. Todavia, o puro status de mercadoria dos trabalhadores nunca existiu completamente na realidade. Variadas formas de proteção pré-capitalistas sempre existiram e novos mecanismos de proteção social emergiram e hão de emergir. Para Esping-Andersen, a principal divergência nas concepções de políticas sociais ocorre entre os conservadores, liberais e socialistas. A gênese e a interpretação da desmercantilização, na perspectiva dessas correntes teóricas, são de grande relevo para se compreenderem as estratégias e concepções adotadas nas políticas sociais, conforme será verificado a seguir.

\section{OS CONSERVADORESEAPRÉ- MERCANTILIZAÇÃO DAS RELAÇÕESSOCIAIS}

Esping-Andersen (1990) argumenta que não se pode confundir a sociedade pré-capitalista com a ausência de formas mercantilistas. A agricultura feudal produzia mais-valia, e as cidades medievais estavam fortemente comprometidas na produção e troca de mercadorias. A economia senhorial ou absolutista cobrava uma tributação que, por sua vez, exigia a venda de mercadorias. Além disso, os produtores pré-capitalistas, camponeses, diaristas e os servos, não dispunham de muita independência e autonomia em relação ao desempenho do trabalho, isto é, os indivíduos não podiam fazer muitas reivindicações quanto à subsis- tência fora do trabalho. Apesar disso, a forma mercantilizada estava menos presente, haja vista que a grande maioria das pessoas não estava completamente dependente da renda proveniente do salário para garantir a sobrevivência.

Naquela época, os domicílios permaneciam frequentemente autossuficientes, assumindo a servidão feudal certo grau de reciprocidade e ajuda paternalista. O produtor urbano, geralmente, era sócio compulsório de alguma corporação de ofício, e os mais destituídos de qualquer ajuda ainda podiam contar com o apoio da igreja. Assim, diferentemente da lógica mercantil do capitalismo, a maioria das pessoas podia contar com a ajuda de organizações comunais e familiares para manter ou ter garantida a subsistência. Em comparação com a ajuda aos pobres do laissez-faire, a assistência pré-capitalista era muito mais generosa e benigna (cf. Esping-Andersen, 1990, p.38).

A característica central da ideologia conservadora está centrada no pressuposto de que a mercantilização é moralmente degradante, favorecedora e pulverizadora da corrupção social. Para os conservadores, os indivíduos não devem ser motivados a competir ou lutar, mas necessitam subordinar o próprio interesse ao poder das autoridades e das instituições. As instituições feudais se opõem, portanto, à mercantilização, uma vez que não consideram o mercado como central. Além disso, o trabalho assalariado ainda não havia sido institucionalizado nos termos atuais. ${ }^{11}$

\footnotetext{
${ }^{11}$ Um exemplo desse tipo de relação é citado por EspingAndersen (1990, p.38-39) com base num fato real. Uma empresa típica do ramo têxtil dos Estados Unidos se instalou no Haiti por volta de 1970. Após a montagem da fábrica, foram escolhidos os melhores trabalhadores do país. Depois de alguns meses, a fábrica foi fechada. A principal razão era que aquela fábrica americana não conseguiu lidar com os arranjos de bem-estar feudais do Haiti, que determinavam que, quando a casa da mãe de um trabalhador é completamente queimada, o chefe da empresa tem a obrigação de resolver isso. Da mesma forma, quando uma criança precisava de atenção médica ou um irmão se casava, novamente era a obrigação do chefe ajudar. Obviamente, os americanos calcularam erroneamente, impondo o salário de mercado como o real salário, pois, quando os trabalhadores são genuinamente mercantilizados, como nos EUA, o gerente não ocupa a função de protetor e pai. Contudo, Esping-Andersen reconhece que formas parternalistas não existem somente em sociedades feudais, mas também em sociedades modernas, como Alemanha, USA, França, Japão etc.
} 
É válido ressaltar que as corporações de ofício constituem a segunda variante pré-capitalista de arranjos desmercantilizados. Elas emergiram nas cidades, entre os artesãos, como um meio de monopolizar a entrada de membros, preços e produção. As corporações de ofício e associações fraternais integravam o pagamento e o recebimento de proteção social, cuidando de sócios inválidos, viúvas e órfãos. Quando as corporações de ofício foram abolidas, elas foram, em sua grande maioria, transformadas em sociedades mútuas. Na Alemanha, as sociedades mútuas e as subsequentes leis de seguro social do imperador Bismarck estavam dotadas do velho espírito feudal, arraigadas na proposta de membrezia compulsória e no princípio da administração própria.

Sem sombra de dúvidas, proposições conservadoras são referências básicas para a compreensão das origens históricas da política social moderna. Em quase todos os países, seja na Suécia, na Inglaterra, ou no continente europeu como um todo, a tradição conservadora foi que forjou os primeiros ataques sistemáticos à mercantilização do trabalho. Primeiramente, porque as forças conservadoras temiam que a marcha avançada do liberalismo, da democracia e do capitalismo destruísse as instituições em que fundamentavam seus poderes e privilégios. A mercantilização do trabalho acabaria com os sistemas feudais e absolutistas de controle sobre os trabalhadores. Em segundo lugar, o status de prémercantilização era um modelo presente no emergente laissez-faire, e as corporações de ofício foram transformadas em sociedades mútuas. Com isso, a empresa capitalista passou a oferecer uma série de benefícios sociais para além do contrato de trabalho. Nesse sentido, pode-se observar que as políticas sociais conservadoras ofereceram as bases para o chamado moderno Estado de Bem-Estar, inicialmente relacionado às leis de seguro social de membrezia compulsória e de administração própria, típicas do modelo Bismarckiano (Esping-Andersen, 1990, p.41).

\section{OS LIBERAIS E A DEFESA DA MERCANTILIZAÇÃO}

Conforme Esping-Andersen (1990), os defensores do laissez-faire foram os responsáveis pela "santificação" da mercantilização. Os liberais argumentam, em primeiro lugar, que a garantia de um mínimo social causaria pobreza e desemprego e não a erradicação da miséria. Essa ideologia encontrou apoio nas recentes teorias acerca do neoliberalismo. Para os liberais, a proteção social causa corrupção moral, desperdício, ociosidade e incentivo aos vícios, como o consumo de bebidas alcoólicas.

A hipótese central do liberalismo pressupõe que o mercado é emancipador, o melhor meio possível para independência e industrialização. Se não houver interferência, o mercado, através do seu caráter autorregulador, assegurará empregos a todos aqueles que tiverem vontade de trabalhar, tornando todos capazes de garantir seu próprio sustento e proteção social. Os problemas sociais não ocorreriam por falhas no sistema, mas como consequência da falta de motivação e de poupança individual.

Segundo Polanyi (2000), o modelo liberal puro de uma "boa sociedade" contém várias debilidades, as quais são óbvias e bastante conhecidas. Os liberais ortodoxos partem da premissa de que todos os indivíduos seriam capazes de participar no mercado, o que é uma tese inconsistente, já que nem todos, os idosos e pessoas com deficiências, possuem condições de participar desse processo e dependem, por conseguinte, da ajuda da família. Por outro lado, a ajuda dispensada aos familiares pode vir a compelir a própria capacidade de a família prover o sustento dos seus e conseguir algum trabalho no mercado. Poupar para eventualidades futuras também não seria uma saída viável, especialmente quando os salários são muito baixos. Ademais, quase nenhum indivíduo pode se salvaguardar de uma crise econômica prolongada. Em todos esses casos, os liberais dogmáticos são forçados a buscar apoio nas instituições pré-capitalistas de assistência social, como 
é o caso da família, da igreja e da comunidade. Ao proceder desse modo, os liberais se contradizem, porque essas instituições não participam das regras do livre jogo das relações de mercado.

Diante do exposto, o liberalismo passa a reconhecer a necessidade de um mínimo de intervenção social, uma vez que a população morreria sem a existência de serviços de saneamento público. Por isso, segundo Esping-Andersen (1990), as forças das circunstâncias levaram o liberalismo a aceitar a inevitabilidade de políticas sociais. Os britânicos descobriram que um império teria dificuldades em se manter sem um exército de soldados saudáveis e bem educados. Da mesma forma, o desempenho de um trabalhador indigente e destituído de proteção social tende a ser bem inferior ao de um trabalhador em condições sociais favoráveis. Isso provavelmente explica a razão pela qual os países mais ricos investem um alto contingente de recursos em proteção social, possuindo um dos melhores desempenhos na área social e econômica, conforme salienta Manow (2007).

Como vimos acima, o liberalismo foi obrigado, por força das circunstâncias, a aceitar a intervenção do Estado nas políticas sociais. A questão central é verificar, então, como a política social foi elaborada no contexto do liberalismo e quais as respostas dos liberais ao dilema da mercantilização. Quanto a esse aspecto, Esping-Andersen (1990, p.42-43) indica duas repostas possíveis:

a) Em primeiro lugar, introduziu-se o princípio $d a$ "menor elegibilidade"12, elemento característico das antigas "leis dos pobres", cuja assistência é prestada via testes de meios, ou seja, comprovação da pobreza ${ }^{13}$ Evita-se, com isso, a extensão de direitos sociais incondicionais, pois os Estados podem avaliar as condições socioeconômicas, impedindo que os trabalhadores escolham as polí-

${ }^{12} \mathrm{O}$ critério de menor elegibilidade pode ser exemplificado no Brasil através do BPC (Benefício de Prestação Continuada), cujo critério de renda é $1 / 4$ do salário mínimo, isto é, o menor índice de avaliação de salários e rendas do IBGE. Os recentes programas assistencias introduzidos no governo Lula obedecem aos mesmos princípios liberais, isto é, a menor ou baixa elegibilidade como critério acesso aos benefícios sociais.

${ }^{13}$ No contexto latino-americano, políticas sociais neoliberais estão sujeitas a comprovação de indigência (cf. Laurell 1997). ticas de assistência em detrimento do trabalho. Um sistema de proteção social orientado pela lógica da comprovação da pobreza visa a assegurar que os benefícios sociais sejam reservados apenas para os denominados incapacitados ${ }^{14} \mathrm{de}$ participar do mercado.

b) Em segundo lugar, o liberalismo nunca contestou a caridade ou a lógica do seguro, de tal modo que a caridade deve basear-se na lógica do voluntariado e os seguros em arranjos contratuais. Nesses casos, os direitos e os benefícios sociais têm de refletir a lógica das contribuições individuais. Para Esping-Andersen (1990), os liberais concordavam com a existência do sindicalismo, pois ele era perfeitamente capaz de estender a ideia do seguro individual através da barganha coletiva de benefícios sociais. Isso teria contribuído para fortalecer as políticas sociais orientadas pelo princípio meritocrático, baseado na lógica dos seguros.

Desse modo, pode-se afirmar que o liberalismo tem uma clara preferência pelo seguro privado, organizado através do mercado. O seguro social, assim como o seguro individual familiar, paga benefícios aos empregados, valorizando o desempenho através do trabalho e das contribuições. O objetivo da lógica do seguro é fortalecer o incentivo ao trabalho e à produtividade, ao invés da assistência não contributiva. Em suma, a lógica liberal acentua o status mercantilizado da força de trabalho, cuja proteção deve limitar-se basicamente às contribuições e ao desempenho individual.

\section{OS SOCIALISTAS E A LUTA PELA DESMERCANTILIZAÇÃO DAS RELAÇÕES SOCIAIS}

Conforme Esping-Andersen (1990), tanto a teoria como a ideologia e a estratégia política do socialismo teriam emergido em resposta ao problema da mercantilização do trabalho. Para os socialistas, a mercantilização do trabalho constituiu-

${ }^{14}$ No Brasil, Potyara Pereira (1998) analisa a LOAS (Lei Orgânica de Assistência Social) sob essa perspectiva. 
se em elemento integral do processo de alienação e de formação de classes sociais. A mercantilização do trabalho é a condição sob a qual os trabalhadores têm de abandonar o controle sobre seu trabalho em troca de salários. Figura ainda como condição sob a qual a dependência do mercado é afirmada, além de ser razão fundamental para a realização de controle dos patrões sobre os trabalhadores. Ademais, a mercantilização seria a causa principal da divisão de classe, representando um grande obstáculo à unidade coletiva dos trabalhadores. Nessa lógica, está intrínseca a competição entre os trabalhadores, de modo que quanto maior for a competição, menor tendem a ser os salários. Por isso, seria natural o desejo de os trabalhadores realizarem a desmercantilização, que se tornou o princípio guia das políticas sociais no cerne dos movimentos dos trabalhadores. Para EspingAndersen (1990), tanto os trabalhadores quanto os movimentos operários dependem da diminuição da dependência da escravização individual, causada pela mercantilização, oriunda da venda da força de trabalho.

Nas teorias socialistas de Karl Marx e Friedrich Engels, especialmente no capítulo final do "Manifesto do Partido Comunista", esses autores propagam uma série de melhorias sociais, as quais aumentariam o poder de pressão dos trabalhadores e fortaleceriam a posição deles perante o mercado. Seguindo a mesma lógica, Karl Kautsky e Rosa Luxemburg lutaram por melhores salários. Para Esping-Andersen (1990, p.44), tanto revolucionários quanto reformistas concordam com a imprescindibilidade de se lutar pelo direito a uma renda aquém do trabalho assalariado. O que dividiu os reformistas e a ala revolucionária do socialismo teria sido, principalmente, a questão da estratégia para alcançar tal fim, ou seja, a garantia de uma renda para além do mercado.

É mister frisar que as políticas sociais, defendidas pelos socialistas, pautadas no princípio da desmercantilização, tiveram inicialmente um parentesco com a tradição corporativa e conservadora. Isso ocorreu na época em que os trabalhadores constituíram sindicatos restritos e sociedades de apoio mútuo. Uma das maiores debilidades das propostas de políticas sociais desses movimentos eram os modestos benefícios concedidos e seu limitado alcance, que excluíam os membros mais vulneráveis do proletariado, isto é, justamente os mais desorganizados, o lumpenproletariado, os quais representavam a maior ameaça à unidade dos trabalhadores. Eram exatamente esses trabalhadores que precisavam ser fortalecidos. No entanto, as sociedades de auxílio-mútuo, microssocialistas, tiveram dificuldade em incorporá-los. Isso ocasionou o debate em torno do apoio dos trabalhadores organizados à extensão dos direitos sociais ao lumpenproletariado no Estado burguês.

Ressalte-se que a extensão de direitos sociais constituiu-se, antes da Primeira Guerra Mundial, num dos dilemas dos socialistas europeus. Para Heimann (1980), ${ }^{15}$ a política social sempre teve um caráter dual: pode muito bem ser um meio para sustentar e legitimar o sistema capitalista e, ao mesmo tempo, configurar como um corpo estrangeiro, um perigo, podando o poder e a hegemonia do capital. Os revolucionários, por sua vez, acreditam que as raízes da revolução estariam nas crises e colapsos do capitalismo; os reformistas, por outro lado, perceberam que a miséria humana, oriunda das crises, apenas debilitaria o projeto socialista. Consequentemente, um aumento gradual da extensão e da qualidade de direitos sociais foi visto pelos socialistas como a pré-condição para a ampliação das lutas e não somente como usufruto de seu sucesso. Na análise de EspingAndersen (1990), por causa dessa reordenação estratégica após os anos de 1960, os socialistas teriam abraçado o Estado de Bem-Estar como foco de um projeto social a longo prazo.

Todavia, conforme salienta EspingAndersen (1990), os socialistas nem sempre tiveram uma concepção política voltada para a defesa da desmercantilização, especialmente no período anterior à Segunda Guerra Mundial. Naquele período, defendiam a tese de que as melhorias sociais deveriam ter como princípio norteador o grau de

${ }^{15}$ Heimann foi um dos teóricos que realizou um trabalho pioneiro entre os contemporâneos de sua época. 
carência. Arraigados nessa concepção, os socialistas operavam nos moldes amplamente liberais, utilizando-se dos testes de meios (comprovação da pobreza). Ademais, as políticas sociais adotavam como principais critérios para aferimento de benefícios sociais as condições de vida dos pobres (pobreza absoluta), ao invés de utilizarem os padrões de vida médios de uma sociedade. Desse modo, os socialistas viam a proteção social como uma forma de "ajudar" os indivíduos que fossem, de fato, pobres e carentes.

Destaque-se que, até a Segunda Guerra Mundial, os socialistas eram fortes defensores do trabalho assalariado e dos trabalhadores assalariados, especialmente do proletariado industrial. Isso significou a defesa exclusiva de determinadas classes sociais. Nesse cenário, o que caracterizava os socialistas da época era a adoção do princípio da defesa dos direitos sociais básicos, mínimos, cujos benefícios deveriam ser modestos e destinados apenas à “classe trabalhadora”. Contudo, quando os socialistas se mobilizaram na defesa de um público mais amplo, ou seja, “classe popular”, houve uma ampliação dos direitos universais. Já nos anos de 1950 até 1960, os partidos socialistas ampliaram o grau de cobertura dos programas sociais, porém com benefícios em quantidade e qualidade modesta, utilizando, na grande maioria dos casos, rígidos critérios de elegibilidade. A meta dos socialistas era o combate à pobreza, ao invés de se lutar pela emancipação dos trabalhadores no que concerne à dependência em relação ao mercado. Após 1970, os socialistas se mobilizaram na defesa da emancipação dos trabalhadores no que concerne à dependência em relação ao mercado, havendo uma ampliação dos direitos para todas as camadas sociais. Nesse veio, Esping-Andersen (1990, p.46) argumenta que as políticas sociais de caráter emancipador deveriam incluir duas questões centrais, elencadas a seguir:

a) a extensão dos direitos além do terreno estreito da carência absoluta;

b) o aumento dos benefícios sociais, visando a se alcançarem os padrões de vida e de renda de uma nação.
Em suma, o que qualifica o conteúdo da desmercantilização no paradigma socialista é a emancipação da dependência exclusiva do mercado e da família. ${ }^{16}$ A questão central do projeto socialista perpassa não somente pela simples existência de direitos sociais, mas ressalta, sobretudo, a qualidade e a arquitetura desses direitos. Ou seja, os direitos sociais devem prover benefícios para além da superação da pobreza absoluta, garantindo aos pobres benefícios que lhes assegurem padrões de vida similares aos da classe média de uma nação. Ao contrário do modelo conservador, a dependência da família, a moralidade e a autoridade não são vistas como um substituto da dependência do mercado. Em contraposição ao liberalismo, o paradigma socialista objetiva maximizar e institucionalizar os direitos sociais, independentemente da inserção ou não do indivíduo no mercado de trabalho. Em síntese, os socialistas defendem uma marginalização do mercado.

\section{DESMERCANTILIZAÇÃO DAS RELAÇÕES SOCIAIS NO MUNDO REAL}

Para compreender o modelo de desmercantilização das políticas sociais, Esping-Andersen elaborou um conjunto de variáveis, cujas características vão além da simples análise dos gastos ou investimentos sociais, acrescentando-se a essa avaliação as regras, os padrões e a qualidade dos programas sociais ofertados. As principais dimensões utilizadas pelo referido teórico foram sintetizadas a seguir (cf. Esping-Andersen, 1990, p.47).

1. Um conjunto de dimensões ocupa-se com as regras de acesso dos indivíduos aos benefícios. De grande relevo são os critérios de elegibilidade e restrições ou facilidade quanto ao acesso dos benefícios ou direitos. Um programa garante um grau elevado de desmercantilização, se o acesso

${ }^{16}$ Essa proposta ficou conhecida como desfamiliarização, que expressa o grau de independência dos indivíduos em relação à família, ou seja, o grau em que o Estado oferece aos domicílios e famílias apoio para que nenhum membro da família seja mais onerado do que o outro nos afazeres domésticos. 
ao programa for fácil ${ }^{17} \mathrm{e}$ se o direito a um nível de vida adequado estiver garantido, independentemente de o indivíduo ter trabalhado, ter tido carteira assinada, ou ter contribuído financeiramente para a previdência social. Além disso, é avaliado o tempo de permanência das pessoas nos programas. Se os direitos sociais tiverem um tempo de permanência muito curto, a capacidade de desmercantilização dessa política social diminui bastante.

2. Um segundo conjunto de dimensões dedica-se à questão da substituição da renda (especialmente em relação ao seguro-desemprego). Faz-se uma avaliação do nível de benefícios, isto é, se eles são substancialmente menores do que os salários normais, ou do padrão de vida considerado adequado e aceitável em determinada sociedade. Quanto menor o nível dos benefícios, maiores são as necessidades de um retorno imediato ao mercado de trabalho.

3. Em terceiro lugar, o conjunto de benefícios ou direitos garantidos faz a diferença. Quase todos os países capitalistas reconhecem vários direitos sociais de proteção contra riscos sociais básicos: desemprego, incapacidade, doença e velhice. Um modelo de proteção altamente avançado existe quando a renda é garantida sem qualquer condicionalidade.

Note-se que os critérios utilizados para mensurar a desmercantilização, no mundo real, incorporam a facilidade do acesso aos benefícios sociais. Quanto maiores e mais rígidos forem os critérios de elegibilidade, maiores serão os empecilhos e dificuldades no acesso aos mecanismos de proteção social. Ademais, a qualidade dos benefícios em relação ao padrão médio de um país faz a diferença. Quanto mais distantes do padrão nacional, menor será o grau de desmercantilização. Por conseguinte, o grau de desmercantilização de um sistema de proteção será maior quando não existirem critérios de seleção rígidos e excludentes.

${ }^{17}$ Gorz (2005) argumenta que, na fase atual do capitalismo, o acesso aos bens materiais e imateriais tornou-se o principal aspecto em disputa. Ou seja, a principal questão está relacionada às limitações estabelecidas institucionalmente às capacidades do poder em limitar sua difusão e de regulamentar o acesso.

\section{ACESSO A BENEFÍCIOS SOCIAIS E PRINCI- PAIS DETERMINANTES DA DESMERCANTILIZAÇÃO}

Os direitos sociais trazem, em seu cerne, a prerrogativa da incondicionalidade, ou seja, devem ser garantidos pelo simples fato de um cidadão pertencer a um determinado território. Entretanto, no mundo real, os direitos sociais quase nunca são totalmente incondicionais. Para se ter acesso a benefícios, os indivíduos têm de se encontrar, pelo menos, em determinadas condições, quais sejam: doença, velhice, e (ou) desemprego. Além da mera presença de um problema, determinados critérios são exigidos, dependendo dos modelos de proteção social adotados por um país. Esping-Andersen (1990, p.48) distingue três sistemas de proteção social, cada qual expressando um impacto diferente em relação à desmercantilização das relações sociais, conforme descrito a seguir.

a) Liberal - Um regime, historicamente predominante nos países Anglo-Saxões, que concebe os direitos sociais através da comprovação de pobreza e da condição de indigência. Esse tipo de sistema social está ancorado na antiga "Lei dos pobres", já que a provisão de benefícios sociais depende da aplicação de testes de meios (comprovação da pobreza), os quais apresentam graus variados de rigidez. Esse sistema não estende plenamente os direitos de cidadania. O que conta, no modelo liberal, é caráter restritivo dos testes de meios e a moderação dos benefícios. Os benefícios são modestos, pois se objetiva não causar falta de incentivos ao trabalho, valorizando-se, consequentemente, a ética do trabalho. Assim, quanto mais restritivos os testes de comprovação da pobreza, menor o grau de desmercantilização. Os países protótipos desse regime são os Estados Unidos da América, Inglaterra e Austrália.

b) Conservador - Esse sistema de proteção social estende benefícios com base no desempenho do trabalho. Essa variante tem suas raízes na tradição do seguro social, que foi desenvolvida primeiramente na Alemanha e, posteriormente, se 
alastrou pelo continente europeu. Os direitos sociais são concebidos de forma condicional, mesclando trabalho-mercado com contribuições financeiras. Normalmente, o acesso a benefícios obedece à lógica do cálculo, ou seja, à concepção de que o indivíduo tem um benefício pessoal em virtude de cumprir um contrato. O grau de oportunidades oferecidas nesse sistema em relação à desmercantilização depende, em grande medida, das exigências da base de cálculo. Em outros termos, calcula-se o tempo durante o qual um indivíduo tem de trabalhar para ter acesso aos benefícios. Quanto maior o tempo de trabalho para garantir o acesso a benefícios, menor o grau de desmercantilização. Os países protótipos desse regime são Alemanha, França e Itália.

c) Social-democrata ou socialista - O terceiro sistema de acesso a benefícios originou-se do princípio universal de direitos de cidadania, concebido com base no relatório de Beveridge (1942). O aspecto inovador nesse tipo de sistema refere-se ao fato de o acesso aos direitos sociais não depender da comprovação da pobreza ou do desempenho no trabalho. A elegibilidade resulta apenas do fato de ser cidadão ou residir num determinado país. Os programas sociais são construídos pelo princípio de distribuição de benefícios, cujos valores são unitários e independem de contribuição anterior. Em virtude disso, esse regime de proteção social possui um grande potencial de desmercantilização, aliás o maior grau em relação aos anteriores. O sistema de proteção social universal é mais forte nos países escandinavos, um princípio há muito tempo existente na tradição socialista de política social. Os países protótipos desse tipo de regime são Suécia, Noruega e Dinamarca.

Por conseguinte, é possível notar que o grau de desmercantilização das políticas sociais está intimamente ligado ao modelo de proteção social em voga. A configuração desses modelos depende quase exclusivamente de variáveis políticas, tais como o grau de organização da classe trabalhadora em sindicados, partidos e movimentos sociais. O quadro a seguir apresenta os resultados dos estudos de
Esping-Andersen (1990) quanto ao grau de desmercantilização no mundo real. No decorrer de sua análise, o autor adota os critérios de facilidade quanto ao acesso aos benefícios sociais como principal aspecto para aferir o grau de desmercantilização. A maior rigidez na acessibilidade das políticas sociais implica, portanto, maior controle social e maiores empecilhos na garantia dos direitos sociais. O Quadro I demonstra que os países do regime social-democrata (socialistas) garantem um grau maior de desmercantilização, ou seja, maior autonomia e liberdade em relação às forças do mercado.

Quadro 1 - Ranking dos países segundo o grau de desmercantilização das políticas sociais

\begin{tabular}{|l|c|}
\hline \multicolumn{1}{|c|}{ PAÍS } & $\begin{array}{c}\text { Grau de } \\
\text { desmercantilização }\end{array}$ \\
\hline Regime Social-Democrata & \\
\hline Suécia & 39,1 \\
\hline Noruega & 38,3 \\
\hline Dinamarca & 38,1 \\
\hline Holanda & 32,4 \\
\hline Bélgica & 32,4 \\
\hline Áustria & 31,1 \\
\hline \multicolumn{1}{|c|}{ Regime Conservador } & \\
\hline Suíça & 29,8 \\
\hline Finlândia & 29,2 \\
\hline Alemanha & 27,7 \\
\hline França & 27,5 \\
\hline Japão & 27,1 \\
\hline Itália & 24,1 \\
\hline & \\
\hline Grã-Bretanha & 13,8 \\
\hline Irlanda & 13,0 \\
\hline Canadá & 23,4 \\
\hline Nova Zelândia & 23,3 \\
\hline EUA & 22,0 \\
\hline Austrália & 17,1 \\
\hline & \\
\hline Regime Liberal & \\
\hline
\end{tabular}

Fonte: Esping-Andersen, 1990. p.52

OQuadro I confirma que os países do regime liberal propiciam menor grau de desmercantilização, ou seja, menos autonomia e liberdade em relação às forças do mercado. A característica principal das políticas sociais liberais é justamente reforçar a dependência dos indivíduos em relação ao mercado. Por outro lado, os socialistas objetivam garantir maior independência e autonomia perante aos mecanismos de mercado. Enfim, os liberais 
defendem maior provisão de benefícios e serviços pela via mercado, enquanto que os socialistas procuram garantir maior independência e autonomia através da garantia de benefícios e serviços pela via Estado, conforme destacaremos a seguir.

\section{A DIVISÃO DE RESPONSABILIDADES ENTRE ESTADO, MERCADO E FAMÍLIA}

Os três sistemas de proteção social descritos anteriormente concebem diferentemente as responsabilidades da proteção social, cujos pilares condizem com a divisão de responsabilidades entre mercado, família e Estado. Numa perspectiva liberal de proteção social, o mercado é tido como o principal recurso de provisão, visto que a maioria dos cidadãos deveria obter uma renda que possibilitasse o sustento através da venda da força de trabalho. Na concepção conservadora, o Estado, por sua vez, deve entrar em cena apenas quando a família e o mercado falham, ou seja, quando os indivíduos não conseguem, por mérito e inserção do mercado de trabalho, garantir para si e os seus um padrão digno de sobrevivência. Segundo Esping-Andersen (2002), nos países católicos do Sul da Europa e na América Latina, a família é o central ente de proteção social, que geralmente entra em cena em decorrência das falhas do mercado e do Estado.

Os socialistas, por outro lado, são os defensores clássicos das soluções coletivas, reconhecem que o mercado e a família são canais insuficientes de proteção social, sendo, inclusive, os principais causadores das desigualdades sociais. Nos casos em que nenhum desses três pilares consegue proteger os cidadãos contra os riscos sociais e econômicos, têm-se casos de déficit e deficiência na esfera da proteção social. Diante disso, EspingAndersen (2002) enfatiza a importância de conceber e implementar políticas sociais numa perspectiva universal, sem rígidos critérios de elegibilidade, a fim de que todos os cidadãos, independentemente de suas condições ou classe social, tenham um padrão digno de sobrevivência. O Quadro 2 apresenta, de forma resumida, as principais diferenças entre os três modelos de políticas sociais. Ele ilustra que os liberais defendem a provisão de benefícios e serviços sociais através de mecanismos de mercado, enquanto os socialistas procuram garantir maior independência e autonomia através da garantia de benefícios e serviços através da intervenção do Estado. Além do papel do Estado, há objetivos e valores diferenciados. Enquanto os liberais têm como propósito garantir a capacidade individual de inserção no mercado, mesmo que isso implique uma maior desigualdade social, os socialistas defendem maior desmercantilização, igualdade e segurança social contra riscos. Os conservadores, por outro lado, baseiam-se no princípio da subsidiaridade, cabendo à família um papel central na proteção social.

\section{CONSIDERAÇÕES FINAIS}

Este artigo procurou tecer reflexões sobre o conceito da desmercantilização na análise das políticas sociais. A desmercantilização permite avaliar o grau de autonomia e independência que as políti-

Quadro 2 - Principais características dos paradigmas de políticas sociais

\begin{tabular}{|l|l|l|l|}
\hline \multicolumn{1}{|c|}{ Concepções } & \multicolumn{1}{|c|}{ Liberais } & \multicolumn{1}{c|}{ Conservadores } & \multicolumn{1}{c|}{ Socialistas } \\
\hline Economia Política & $\begin{array}{l}\text { Liberalismo } \\
\text { Laissez-faire }\end{array}$ & $\begin{array}{l}\text { Conservadorismo } \\
\text { Corporativismo }\end{array}$ & Estatismo \\
\hline Objetivos e Valores & $\begin{array}{l}\text { Capacidade de inserção no } \\
\text { mercado, liberdade }\end{array}$ & $\begin{array}{l}\text { Segurança, subsidiaridade, } \\
\text { manutenção do status }\end{array}$ & $\begin{array}{l}\text { Desmercantilização, } \\
\text { igualdade e segurança } \\
\text { social contra riscos }\end{array}$ \\
\hline $\begin{array}{l}\text { Central na produção de } \\
\text { responsabilidade social }\end{array}$ & Mercado & Família & Estado \\
\hline Protótipos de países & EUA & Alemanha & Suécia \\
\hline
\end{tabular}

Fonte: Elaboração própria baseada em Esping-Andersen, 1990. p.38-47. 
cas sociais concebem aos indivíduos ou famílias para que possam sobreviver para além das relações do mercado.

É notável que a concepção de desmercantilização difira das teorias vigentes até o momento, por não enfatizar somente a quantidade, mas, especialmente, a qualidade das políticas sociais institucionalizadas, medidas pelo grau em que indivíduos podem manter um nível de vida tolerável, independentemente da obrigação da participação no mercado de trabalho. A dimensão da desmercantilização incorpora a possibilidade de os cidadãos poderem, livremente, optar por não trabalhar, quando assim considerarem necessário, sobretudo quando há um alto grau de exploração da força de trabalho.

Ao contrário do propagado pela mídia, pelo senso comum e por concepções liberais e conservadoras, bem como por parte da esquerda ortodoxa brasileira, ${ }^{18}$ as políticas sociais desmercantilizadoras, na concepção de Esping-Andersen, fortaleceriam o movimento dos trabalhadores e enfraqueceriam o poder dos patrões, sendo, inclusive, uma pré-condição para que os trabalhadores sejam capazes de agir coletivamente. $\mathrm{O}$ estudo em tela demonstrou que os liberais e, recentemente, os neoliberais priorizam veementemente as políticas de caráter mercantilizado, enquanto que os socialistas defendem as políticas que conduzem à desmercantilização das relações sociais.

Em relação à divisão das responsabilidades sociais, a análise da literatura existente revelou que o fortalecimento da capacidade de atuação do Estado é fundamental para corrigir as limitações, defeitos e (ou) falhas do mercado e da família na garantia de um padrão de vida tolerável. Os neoliberais, por seu turno, defendem a valorização do papel do mercado e a diminuição do papel do Estado no provimento de políticas sociais. O Estado é visto pelos neoliberais como ente responsável pelo surgimento de comportamentos taxados de acomodação, falta de vontade para o trabalho,

${ }^{18}$ Comumente defensores da tese de que as políticas sociais tornariam os pobres apáticos, acomodados, preguiçosos e dependentes. dependência e preguiça. Os neoliberais defendem, portanto, a volta do individualismo e o fortalecimento da capacidade das pessoas de obterem sucesso individual no mercado. Eles partem do pressuposto de que os riscos sociais e as desigualdades surgidas no mercado poderiam ser corrigidos, se todos puderem competir em pé de igualdade, 0 que não ocorre no mundo real. Por outro lado, os conservadores e católicos sociais defendem o favorecimento do papel central da família e das comunidades locais no provimento de serviços de proteção social, ainda que tais serviços não tenham condições, por si sós, de atingir tal fim. Por último, os socialistas defendem soluções coletivas na provisão de políticas de proteção social, posto que o mercado e a família seriam canais insuficientes de seguridade, figurando como os principais causadores das desigualdades sociais.

No Brasil, nota-se a predominância de políticas sociais baseadas em concepções liberais, nas quais os critérios de elegibilidade são definidos e estabelecidos através de rígidos testes de meios, a exemplo do Benefício de Prestação Continuada e do Bolsa Família. Numa perspectiva social-democrata, esses benefícios deveriam ser bem mais generosos, havendo a extinção dos testes de meio, o caráter vexatório de comprovação da pobreza e as demais condicionalidades.

Ademais, a seleção e o controle das condicionalidades das políticas sociais brasileiras, além de limitar o alcance e qualidade da proteção social, comprometem o número de pessoas que podem acessar esses programas. Numa perspectiva universal, deveria haver a garantia de um padrão de vida razoável, que é comprometido diante do critério da exigência da permanência na pobreza absoluta para a continuidade do acesso ao benefício. Diante disso, percebe-se o baixo grau de desmercantilização dos programas sociais que enfatizam o provimento de políticas seletivas e de baixo alcance quantitativo e qualitativo. Uma exceção no Brasil, apesar das restrições ao acesso, constitui-se o regime de segurado especial da previdência rural, baseado no princípio universal, cujo alcance é maior e, por sua vez, garante um grau 
significativo de desmercantilização. Todavia é mister repensar a concepção das políticas sociais brasileiras, tomando como referência as contribuições de Esping-Andersen, isto é, desmercantilizar as relações sociais, oferecer alternativas para além do mercado, garantindo autonomia, independência. Nas palavras de Amartya Sen (2000), aumentar as possibilidades de escolha dos indivíduos. Para Sen (2000), somente haverá desenvolvimento se houver a ampliação das possibilidades de escolha, garantidas pelas oportunidades de expansão das potencialidades humanas. Nesse quesito, ao contrário do que indica a mídia e o senso comum brasileiro, tanto para Esping-Andersen quanto para Amartya Sen, o Estado é o ente mais apropriado para garantir a independência, a liberdade e a autonomia dos indivíduos, com vistas a marginalizar o mercado. Assim, políticas sociais com maior grau de desmercantilização implicam a garantia de um padrão de vida aceitável, tendo em vista a autonomia e a liberdade dos cidadãos no que concerne aos ditames e imposições do mercado.

(Recebido para publicação em outubro de 2008) (Aceito em janeiro de 2009)

\section{REFERÊNCIAS}

ARRETCHE, Marta. Emergência e desenvolvimento do Welfare State: teorias explicativas. BIB: Revista Brasileira de Informação Bibliográfica em Ciências Sociais, Rio de Janeiro, Anpocs, n. 39, p. 3-40,1995.

BANGURA, Yusuf (Org.) Democracy and social policy development. Basingstoke: UNRISD e Palgrave Macmillan, 2007.

DRAIBE, Sonia; RIESCO, Manuel. Estado de Bienestar, desarrollo económico y ciudadanía: algunas lecciones de la literatura contemporánea. Mexico, DF, CEPAL, 2006. (Serie estudios y perspectivas, 55).

ESPING-ANDERSEN, Gosta. The three worlds of welfare capitalism. Cambridge: Polity, 1990.

Social foundations of postindustrial cconomies. Oxford: Oxford University, 1999.

. Toward a good society, once again? In:

Why we need a new welfare state. Oxford: Oxford University, 2002. p. 1-25.

FARIA, Carlos A. P. Uma genealogia das teorias e modelos do Estado de Bem-Estar-Social. BIB:Revista Brasileira de Informação Bibliográfica em Ciências Sociais, Rio de Janeiro, Anpocs, n. 46, p. 39-71, 1998.

FONSECA, Ana M. Medeiros. Família e política de renda mínima. São Paulo: Cortez, 2001.
GIDDENS, Anthony. Para além da esquerda e direita. São Paulo: UNESP, 1996.

GORZ, André. O imaterial: conhecimento, valor e capital. São Paulo: Annablume, 2005.

LAURELL, Asa. Avançando em direção ao passado: a política social no neoliberalismo. In: (Org.) Estado e políticas sociais no neoliberalismo. 2.ed. São Paulo: Cortez, 1997. p. 151-178.

LENHNARDT, Gero; OFFE, Claus. Staatstheorie und Sozialpolitik. Politisch-soziologische Erklärungsansätze für Funktionen und Innovationsprozesse der Sozialpolitik. In: Funktionen und Innovationsprozesse der Sozialpolitik. In: aufsätze zur politischen soziologie. Frankfurt/Main: Campus Verlag, 2006. p. 153-180.

MARSHALL, T.H: Política social. Rio de Janeiro, Zahar, 1976.

MARX, Karl; ENGELS, Friedrich. Manifest der kommunistischen Partei. Stuttgart: Reclam, 1989.

MERRIEN, Fançois-Xavier. Os Estados-Providência e o futuro - uma releitura crítica de pesquisas recentes. In: CARVALHO, Denise de; BICALHO, Nair; DEMO, Pedro (Org.) Novos paradigmas da política social. Brasília: UNB, 2002. p. 51-90.

MANOW, Philip. As vantagens institucionais comparativas dos regimes de Estado de bem-estar social e as novas coalizões na sua reforma. In: DELGADO, M.; PORTO, Lorena. (Org.) O Estado de Bem-Estar Social no século $X X$. São Paulo: LTR, 2007. p.160-186.

OPIELKA, Michael. Sozialpolitik: grundlagen und vergleichende perspektiven. Hamburg: Rowohlt, 2004.

PEREIRA, Potyara. A política social no contexto da seguridade social e do Welfare State: a particularidade da assistência social. Revista Serviço Social e Sociedade. São Paulo, n. 56, p. 60-76, 1998.

POLANYI, Karl. A grande transformação. 2.ed. Rio de Janeiro, Campus, 2000.

SCHMIDT, Manfred; OSTHEIM, Tobias; SIEGEL, Nico; ZOHLNHÖFER, Reimut (Org.). Der wohlfahrtstaat. Eine Einführung in den historischen und internationalen Vergleich. Wiesbaden: VS Verlag, 2007.

SEN, Amartya. O desenvolvimento como liberdade. 5.ed. São Paulo: Companhia de Letras, 2000.

ULLRICH, Carsten. Soziologie des Wohlfahrtstaates. Eine Einführung. Frankfurt: Campus, 2005.

WEISSHEIMER, Marco Aurélio. Bolsa família: avancos, limites e possibilidades do programa que está transformando a vida de milhões de famílias no Brasil. São Paulo: Fundação Perseu Abramo, 2006 


\section{THE PRINCIPLE OF DECOMMODIFICATION IN THE SOCIAL POLITICS}

\author{
Clóvis Roberto Zimmermann \\ Marina da Cruz Silva
}

The present paper discusses an innovative principle, denominated of decommodification, formulated recently by Esping-Andersen (1990, 1999 2002) and incorporated to the study of social policies. The author's main proposition, through the term decommodification, consists of evaluating the degree of autonomy and independence of individuals in relation to market. The essential conclusions from this analysis evidence a singular and innovative contribution, when emphasizing the importance of the institutional arrangements of the social policies, considering not only rights and warranties, but, above all, the interlacement of the State with market and family in the provision of social policies.

KEYwORDS: decommodification, social policies, social protection, Welfare States.

\section{LE PRINCIPE DE DECOMMODIFICATION (DEMARCHANDISATION), DANS LES POLITIQUES SOCIALES}

\author{
Clóvis Roberto Zimmermann \\ Marina da Cruz Silva
}

Lobjectif de cet article est d'établir des discussions sur le principe innovateur de decommodification (démarchandisation), formulé récemment par EspingAndersen $(1990,1999,2002)$ et incorporé aux études de politiques sociales. En utilisant le terme decommodification (démarchandisation), l'auteur propose essentiellement d'évaluer le degré d'autonomie et d'indépendance des individus face au marché. Les principales conclusions découlant de l'écran d'analyse mettent en évidence une contribution unique et innovatrice qui montre l'importance des arrangements institutionnels des politiques sociales en considérant non seulement les droits et les garanties mais surtout l'imbrication de l'Etat avec le marché et la famille en termes de politiques sociales.

MoTS-CLÉs: decommodification (démarchandisation), politiques sociales, protection sociale, Etats de BienEtre Social.

Clóvis Roberto Zimmermann - Doutor em sociologia pela Universidade de Heidelberg na Alemanha. Atualmente, é professor adjunto de Ciências Políticas da Universidade Federal do Recôncavo da Bahia (UFRB) em Cachoeira e Relator Nacional para o Direito à Alimentação e Terra Rural. Autor do livro Politische Partizipation in Brasilien: Ein Vergleich der Stadtplanungsmodelle von Porto Alegre und Curitiba. Frankfurt am Main/ Londres: IKO-Verlag für interkulturelle Kommunikation, 2006.

Marina da Cruz Silva - Doutoranda em Psicogerontologia pela Universidade de Erlangen-Nürnberg na Alemanha e professora assistente do Curso de Serviço Social da Universidade Federal do Recôncavo da Bahia (UFRB) em Cachoeira. Autora do livro Gedächtnis - und Psychomotoriktraining im Alter: Transfer und Wirksamkeit. Berlin: VDM Verlag Dr. Mueller, 2007. 